\title{
Slotting Allowances and Manufacturers' Retail Sales Effort
}

\author{
ØYSTEIN FOROS \\ HANS JARLE KIND \\ JAN YNGVE SAND
}

CESIFO WORKING PAPER NO. 2396

CATEGORY 9: INDUSTRIAL ORGANISATION

SEPTEMBER 2008

\footnotetext{
An electronic version of the paper may be downloaded

- from the SSRN website:

www.SSRN.com

- from the RePEc website:

- from the CESifo website:

www.RePEc.org

www.CESifo-group.org/wp
} 


\title{
Slotting Allowances and Manufacturers' Retail Sales Effort
}

\begin{abstract}
A manufacturer's incentives to undertake non-contractible investments depend on the profit margin on her sales to the retailer, and slotting allowances can facilitate such incentives by increasing unit wholesale prices. At first glance, it is tempting to conclude that slotting allowances should be particularly prevalent for product categories where the manufacturer's scope for undertaking non-contractible sales effort is relatively large. At odds with this, The Federal Trade Commission, among others, reports that slotting allowances are more commonly used for product categories where the scope for non-contractible effort by the manufacturer is presumably relatively small. To scrutinize this puzzle we set up a simple model with one manufacturer and one retailer, where the manufacturer undertakes noncontractible demand-enhancing investments. The predictions from the model are consistent with the market observations. In particular, we show that even a retailer with complete bargaining power may actually find it optimal to pay the manufacturer a franchising fee if demand is highly sensitive to the manufacturer's non-contractible sales effort. For product categories where the scope for non-contractible effort is relatively small, on the other hand, we are more likely to see slotting allowances.
\end{abstract}

JEL Code: L0.

Keywords: slotting allowances, non-contractible sales effort, bargaining power.

Øystein Foros

Norwegian School of Economics and

Business Administration

Helleveien 30

Norway - 5045 Bergen

oystein.foros@nhh.no
Hans Jarle Kind

Norwegian School of Economics and Business Administration

Helleveien 30

Norway - 5045 Bergen

hans.kind@nhh.no

Jan Yngve Sand

Department of Economics and Management, NFH

University of Tromso,

Norway - 9037 Tromsø

Jan.Sand@nfh.uit.no

August 21, 2008

We would like to thank Derek Clark, seminar participants at the University of Tromsø, and participants at EARIE 07 in Valencia, for valuable comments. Hans Jarle Kind would like to thank CESifo for good working conditions. 


\section{Introduction}

Slotting allowances, which are fixed fees that manufacturers pay to retailers, are widespread in the grocery industry (Bloom et al., 2000, Lariviere and Padmanabhan, 1997). Such fees have also become common in e.g. bookstores, drugstores and record stores (Klein and Wright, 2007, Wilkie et al., 2002). There are two schools of thought that dominate the debate on their effects. The market power school argues that slotting allowances are anti-competitive, for instance by mitigating competition among retailers (Shaffer, 1991) or by reducing product variety through foreclosure of smaller suppliers and/or retailers (Marx and Shaffer, 2007, Shaffer, 2005). The efficiency school, on the other hand, argues that slotting allowances are efficiency enhancing in the sense that they solve channel coordination problems. The two schools of thought are not necessarily inconsistent, though. First, anti-competitive and efficiency rationals for using slotting allowances may certainly coexist. Second, they share the prediction that slotting allowances are more likely the larger the retailers' bargaining power over the manufacturers.

The Federal Trade Commission (FTC, 2003) accentuates three potential efficiency rationales for the use of slotting allowances; signalling the quality of a new product; screening among several new products; and increasing manufacturers' incentives to make demand-enhancing investments. A number of papers analyze the effect of asymmetric information, where slotting allowances are used as a signalling or screening device (Chu, 1992, Lariviere and Padmanabhan, 1997, and Desai, 2000, among others). In the present paper we address how slotting allowances may help to reduce channel coordination problems when manufacturers can undertake demandenhancing investments which are difficult to observe and/or verify for the retailers. Such investments are by their very nature more or less non-contractible (see discussion by e.g. Lal, 1990, and Desai, 1997).

A manufacturer's incentives to undertake non-contractible investments depend on the profit margin on its sales to the retailer and not on total channel profit per se. According to FTC (2003), "Slotting allowances can facilitate these incentives by allowing manufacturers to charge higher wholesale prices (thus higher variable 
margins for the manufacturer) while compensating the retailer through the slotting fee." Along the same line, Farrell (2001) uses contract theory to argue that the combination of slotting allowances and relatively high wholesale prices may be used to facilitate manufacturers' choice of e.g. advertising, packaging, and warehousing.

FTC (2001) reports that the use of slotting allowances varies significantly across product categories. Slotting allowances are heavily used for non-perishable product categories, such as frozen food and dry grocery, while they are less frequently employed for perishable product categories like fresh food, produce, and deli. Sudhir and Rao (2006) analyze new product introductions, and find variations in the use of slotting allowances across product categories which are largely consistent with the FTC-findings. ${ }^{1}$ Interestingly, manufacturers' non-contractible effort is presumably more important for perishable than non-perishable product categories (for perishable products like fresh food, a significant part of manufacturers' demand-enhancing effort cannot be observed and verified). ${ }^{2}$ The empirical findings by FTC (2001) and Sudhir and Rao are thus puzzling, and seemingly inconsistent with the prediction that manufacturers' non-contractible investments are an important rationale behind the usage of slotting allowances.

In this paper we try to give an explanation for the puzzle through a simple twostage game between a downstream firm ("retailer") and an upstream firm ("manufacturer"). At the last stage the retailer sets the end-user price, and the manufacturer decides if and how much to invest in non-contractible sales effort. At the first stage there is a Nash bargaining game between the manufacturer and the retailer over the wholesale contract. The wholesale contract consists of a linear wholesale price in addition to either a slotting allowance (a fixed payment from the manufacturer to the retailer) or a franchising fee (a fixed payment from the retailer to the manufacturer).

\footnotetext{
${ }^{1}$ See also Kuksov and Pazgal (2007) and Klein and Wright (2007).

${ }^{2}$ This is likely to be true also for the delivery phase. Perishable goods are for instance commonly distributed through DSD (direct store delivery), and are often sensitive to e.g. temperature, storing and the chauffeur's driving style during transportation. The manufacturer's effort to ensure high quality along such dimensions is typically difficult to verify and make contractible. Non-perishable goods, on the other hand, are more regularly distributed through the warehouse/logistics system of the retailer than through DSD, leaving less discretion to the manufacturer.
} 
Consistent with FTC's prediction, we show that it may be in the retailer's own interest to pay the manufacturer a unit wholesale price above marginal costs. Otherwise the manufacturer will have no incentives to make demand-enhancing noncontractible investments. However, in contrast to conventional wisdom we find that the unit wholesale price is not necessarily higher with than without slotting allowances. Indeed, the opposite may be true. The reason for this is that if the wholesale contract only specifies a unit price and no fixed fee, the retailer has no incentives to care about total channel profit. He cares only about his own profit, i.e. how much he sells in the end-user market and at which profit margin. He may, therefore, find it profitable to pay such a high unit wholesale price that the manufacturer undertakes larger demand-enhancing investments than what is optimal from a channel point of view.

With a two-part wholesale tariff the aggregate profit will be distributed between the retailer and the manufacturer according to their bargaining power. They will consequently have a common interest in maximizing channel profit, and neither of the parties will have incentives to stimulate demand above what maximizes aggregate profit. This explains why the unit wholesale price - and thus demand-enhancing non-contractible investments - may be lower with than without two-part tariffs. We further show that if the marginal effort costs are sufficiently small, it may be optimal for the retailer to pay such a high unit wholesale price that the manufacturer will not expect to observe any demand unless she invests in sales effort. However, if the manufacturer invests in this case, his operating profit will be too low to cover the cost of undertaking the effort level which maximizes channel profit. In order for the manufacturer's participation constraint to be fulfilled, the retailer pays a franchising fee.

We emphasize that our focus is on non-contractible sales effort. Obviously, sales effort like promotion from manufacturers potentially play an important role in stimulating demand for most kinds of goods. What matters for our analysis is not the size of sales effort as such, but whether demand is sensitive to non-contractible sales effort by the manufacturer. 


\subsection{Some Related Literature}

Shaffer (1991), who may be considered the founder of the market power school, analyzes competition between two retailers in the end-user market. He assumes that the retailers have complete bargaining power over manufacturers, and shows that a high wholesale price may help to soften retail competition and increase end-user prices. Consumers are harmed, but channel profit increases, and is captured by the retailers through slotting allowances. ${ }^{3}$ By the same token, in the present context slotting allowances may increase both the wholesale and the end-user price. Other things equal, this has a negative effect both on the retailer and on the consumers. However, the higher wholesale price increases the manufacturer's investment incentives in e.g. quality control, and we show that this effect may be so strong that both retailer profit and consumer surplus are higher with than without slotting allowances. ${ }^{4}$

The present analysis is most closely related to the strand of literature that analyzes how vertical restraints can solve channel coordination problems. Since bargaining power conventionally has been assumed to be in the hands of the manufacturer (the franchisor), the majority of papers focus on non-contractible sales effort by the retailer (the franchisee). If the manufacturer has all the bargaining power, and the retailer is the one who makes unobservable sales effort, we will in absence of vertical restraints have a standard double marginalization problem. In this case the manufacturer may achieve the same outcome as under channel integration by using

\footnotetext{
${ }^{3}$ In an extension of Shaffer (1991), Foros and Kind (2008) show that when retail chains are forming buyer groups for procurement activities, slotting allowances may be used to dampen intraretailer competition even if rival retail chains cannot observe the wholesale contracts. As mentioned above, there have also been concerns that slotting allowances may have anti-competitive effects through foreclosure of smaller suppliers and/or retailers, see Shaffer (2005) and Marx and Shaffer (2007).

${ }^{4}$ Under asymmetric information, where the manufacturer has private information about e.g. product quality, slotting allowances may be used as a signaling or screening device (Chu, 1992, Lariviere and Padmanabhan, 1997, and Desai, 2000). Slotting allowances may also be used to balance the risk between manufacturer and retailers regarding new products (Sullivan, 1997). Bloom et al. (2000) and Rao and Mahi (2003) find no support for slotting allowances as a signaling device in the grocery industry. In contrast, Sudhir and Rao (2006) and Sullivan (1997) find some empirical support for the signaling rationale.
} 
a two-part tariff, i.e. a franchising fee in addition to a unit wholesale price (see e.g. Lal, 1990). Lal (1990), Desai (1997) and Rao and Srinavasan (1995) assume that both the retailer and the manufacturer undertake value-adding sales effort that cannot be observed by the other party. Lal (1990) argues that an ancillary restraint (in addition to a two-part tariff) is needed only if both the manufacturer and the retailer undertake non-contractible sales effort. Below, we show that this need not be the case: a two-part tariff is unable to achieve the outcome with channel integration even if only the manufacturer undertakes non-contractible sales effort.

The channel coordination problem is thus more complex if the manufacturer is the one that makes non-contractible effort compared to the case where the retailer makes such effort. The reason is that when the retailer makes non-contractible effort, he will internalize the demand-enhancing effect of this effort when he sets the end-user price. A two-part tariff is then sufficient to replicate the outcome under channel integration (see e.g. Lal, 1990). In contrast, a manufacturer can only be induced to make non-contractible effort to the extent that the unit wholesale price is set above marginal production costs. However, this will at the same time induce a double marginalization problem, and a two-part tariff is not sufficient to achieve the same outcome as under channel integration.

In a recent paper Kuksov and Pazgal (2007) discuss the role of retail competition and bargaining power. They abstract from manufacturer investments, and show that slotting allowances cannot arise in equilibrium in absence of retail competition. Like us, they scrutinize on the puzzle that slotting allowances are more frequently used for less perishable products. In their model tougher retail competition leads to more slotting allowances, and competition is more intense for non-perishable products. Hence, Kuksov and Pazgal (2007) and the present paper may offer complementary and mutually reinforcing explanations for the above mentioned puzzle.

\section{The Model}

We consider a channel model with one retailer and one manufacturer, where the manufacturer may undertake non-contractible sales effort that increase the consumers' 
willingness to pay for the good sold by the retailer in the end-user market. ${ }^{5}$

The retailer faces the linear demand curve $\widetilde{q}=v+x-p+\epsilon$, where $v$ is the market potential, $x$ is the level of sales effort by the manufacturer, $p$ is the retail price, and $\epsilon$ is an uncertainty term with mean zero. Defining $E[\widetilde{q}] \equiv q$, expected demand can be written as

$$
q=v+x-p .
$$

The manufacturer's cost of providing sales effort is given by $C(x)=\phi x^{2} / 2$, and is independent of the quantity sold in the retail market. This specification corresponds to the case where the sales effort for instance consists of different kinds of promotion activities, advertising outlays and product quality controls. Our interpretation of the parameter $\phi$ is related to the degree to which non-contractible effort can be undertaken. A low value of $\phi$ is taken to imply that there is substantial scope for non-contractible effort, whereas a high value implies that it is more difficult to exert such effort. We thus interpret $\phi$ as the sensitivity of demand with respect to the manufacturer's sales effort. In the formal model, however, $\phi$ affects the manufacturer's cost of sales effort, but does not affect consumer demand directly. We do this for the sake of simplicity, and the qualitative results would be similar if we had put restrictions on consumers' utility rather than on the cost of effort. ${ }^{6}$

In order to ensure that the second-order conditions are satisfied in all the cases we consider below, we shall make the following assumption:

\section{Assumption: $\phi>1 / 2$}

Upstream marginal costs equal $c$, and we normalize the channel's unit costs at the downstream level to zero.

\footnotetext{
${ }^{5}$ We abstract from the possibility that the parties undertake contractible sales effort, since the model otherwise becomes more complex without adding any new insight. The consequences of allowing the retailer to undertake non-contractible sales effort are discussed in the Introduction.

${ }^{6}$ If the manufacturer's sales effort is observed and verified by the retailer, the level of effort may be agreed on directly in a contract. For some type of advertising the level of outlays may be observed, but it may nonetheless be difficult to verify the effort level (see the Introduction). In general, it is unlikely that it is possible to write complete and enforceable contracts on retail sales efforts.
} 


\subsection{Benchmark: The Integrated Channel}

Channel profit is maximized by solving the optimization problem

$$
\max _{p, x} \pi_{i c}=(p-c) q-\frac{\phi x^{2}}{2}
$$

where subscript ic is short-hand for integrated channel.

The integrated channel's first-order conditions read

$$
\frac{\partial \pi_{i c}}{\partial x}=0=>(p-c)-\phi x=0 \text { and } \frac{\partial \pi_{i c}}{\partial p}=0=>q+(p-c) \frac{d q}{d p}=0,
$$

where we note for later use that $\partial \pi_{i c} / \partial p=0$ can be reformulated as

$$
p=\frac{v+x}{2}+\frac{c}{2}
$$

Solving the expressions in (3) simultaneously we find

$$
x_{i c}=\frac{1}{2 \phi-1}(v-c), \quad p_{i c}=\frac{(v+c) \phi-c}{2 \phi-1} .
$$

The FOCs describe an equilibrium if $\phi>1 / 2$, in which case channel profit equals

$$
\pi_{i c}=\frac{\phi}{2(2 \phi-1)}(v-c)^{2}
$$

\subsection{The Disintegrated Channel}

In the rest of the paper we consider a disintegrated channel, such that the retailer and the manufacturer non-cooperatively maximize profit. Total channel profit in the disintegrated channel is given by

$$
\Pi=\pi_{r}+\pi_{m}
$$

We analyze the following two-stage game:

At stage 1 there is a Nash bargaining game over a wholesale tariff $T(w, S)=$

$w q-S$, where $w$ is the unit wholesale price and $S \gtreqless 0$ is a fixed fee. If $S>0$ the manufacturer pays the retailer a slotting fee, while we have a franchising fee if 
$S<0$. At stage 2 the manufacturer's sales effort $(x)$ and the retailer's choice of end-user price $(p)$ are determined simultaneously. ${ }^{7}$

The profits of the retailer (subscript $r$ ) and the manufacturer (subscript $m$ ) are consequently given by respectively

$$
\pi_{r}=(p-w)(v+x-p)+S
$$

and

$$
\pi_{m}=(w-c)(v+x-p)-\frac{\phi}{2} x^{2}-S
$$

\subsubsection{Stage 2}

We solve the game by using backward induction. Since the outcome of the second stage neither depends on the sign or size of $S$ nor on the distribution of bargaining power, the first-order conditions for stage 2 are found by solving $\partial \pi_{m} / \partial x=$ $\partial \pi_{r} / \partial p=0$ in equations (7) and (8). We thus have

$$
\frac{\partial \pi_{m}}{\partial x}=0=>(w-c)-\phi x=0 \text { and } \frac{\partial \pi_{r}}{\partial p}=0=>q+(p-w) \frac{d q}{d p}=0 .
$$

The retailer will never sell the good below his marginal costs. This means that we must have $p \geq w$. Comparing equations (3) and (9) we therefore immediately see that the effort level in the disintegrated channel is (weakly) lower than the one which maximizes total profit for a given $p$. The reason is that the integrated channel makes effort investments until the entire channel's marginal profit $(p-c)$ is equal to marginal investment costs $(\phi x)$, while the disintegrated channel invests only up to the point where the manufacturer's marginal profit $(w-c)$ equals marginal investment costs $(\phi x)$.

\footnotetext{
${ }^{7}$ If we had included contractible sales effort, it might be natural to assume that this activity takes place at stage 1 . Non-contractible sales effort, on the other hand, should be modelled as taking place in the last stage, since it has no commitment value. Note also that it is reasonable to assume that the wholesale tariff is decided before retail prices. This is due to the fact that retailers do not have long-term contracts with their customers, while the wholesale contractual arrangements are often fixed for no less than one year (see e.g. discussion by Rey and Stiglitz, 1995).
} 
Solving $\partial \pi_{r} / \partial p=0$ we find

$$
p=(w+x+v) / 2,
$$

which means that the retailer sets an end-user price which is increasing in his marginal costs $(w)$. In contrast, for the integrated channel it follows from $\partial \pi_{i c} / \partial p=0$ that $p=(c+x+v) / 2$. Other things equal, the end-user price will therefore be higher in the disintegrated channel if $w \geq c$ (double marginalization). However, since the effort level $x$ will be relatively low in the disintegrated channel, we cannot ascertain at the outset whether the end-user price will be lower in the disintegrated or the integrated channel.

Solving the two FOCs in (9) simultaneously yields

$$
p(w)=\frac{v+w}{2}+\frac{w-c}{2 \phi} \text { and } x(w)=\frac{w-c}{\phi} .
$$

The simple expressions in equation (11) indicate that there will be a trade-off when the wholesale tariff is determined at stage 1: A higher value of $w$ increases the retailer's marginal costs and may lead to an excessively high end-user price, but will also give the manufacturer stronger incentives to make effort investments. Indeed, the manufacturer will not make any investments unless the profit margin is positive; if $w \leq c$ she will optimally set $x^{*}=0$.

Since the manufacturer's effort level is non-contractible, she might have incentives to shirk and set $x=0$ unless the contract between the manufacturer and retailer makes this unprofitable. For the analysis to follow it is now useful to note the following:

Remark 1: Suppose that the manufacturer sets $x=0$. Then expected demand is positive if and only if $w<v$.

Proof: Inserting for (10) into the demand function (1) we find $q=(v-w+x) / 2$. It follows that with $x=0$ we have $q>0$ iff $w<v$, i.e. if the unit wholesale price is strictly below the consumers' willingness to pay for the good when the manufacturer makes no effort. Q.E.D. 
Combining (7), (8), and (11) we find that the first-order conditions at stage 2 give rise to the following profit levels:

$$
\pi_{r}=\left[\frac{(v-w) \phi+(w-c)}{2 \phi}\right]^{2}+S \quad \text { and } \quad \pi_{m}=\frac{(v-w)(w-c)}{2}-S
$$

\subsubsection{Stage 1}

We assume a Nash bargaining game, where the bargaining power of the manufacturer is $\alpha \in[0,1]$ and the retailer's bargaining power is $1-\alpha$. At stage 1 we thus solve

$$
\{w, S\}=\arg \max \left(\pi_{m}\right)^{\alpha}\left(\pi_{r}\right)^{1-\alpha}
$$

where $\pi_{m}$ and $\pi_{r}$ are the profits if both parties accept the agreement. The disagreement point is assumed to be zero. The first order conditions with respect to $S$ and $w$ are given by respectively

$$
\begin{gathered}
\alpha \pi_{r} \frac{d \pi_{m}}{d S}+(1-\alpha) \pi_{m} \frac{d \pi_{r}}{d S}=0 \\
\alpha \pi_{r} \frac{d \pi_{m}}{d w}+(1-\alpha) \pi_{m} \frac{d \pi_{r}}{d w}=0 .
\end{gathered}
$$

By using equations (7) and (8) we can solve equations (13) and (14) to find that

$$
\begin{gathered}
w^{*}=v-\frac{N(\phi)}{N(\phi)+\phi}(v-c) \text { and } \\
S^{*}=\left(\frac{N(\phi)}{N(\phi)+\phi}-\frac{\phi+2}{2} \alpha\right) \frac{\phi(v-c)^{2}}{2(N(\phi)+\phi)},
\end{gathered}
$$

where $N(\phi) \equiv \phi^{2}+\phi-1$. The denominator $(N(\phi)+\phi)$ is positive in the relevant area, i.e. for $\phi>1 / 2$.

With a two-part tariff, the fixed fee will be used to distribute aggregate profit between the manufacturer and the retailer according to their bargaining power (the higher the manufacturer's bargaining power, the smaller the slotting fee: $d S^{*} / d \alpha<$ $0)$. The firms consequently have a common interest in choosing the unit wholesale price so as to maximize total channel profit. This explains why $w^{*}$ is independent of the distribution of bargaining power $\alpha$. 
From equation (15) we further have $w^{*}-c=\phi \frac{v-c}{N(\phi)+\phi}$, which shows that the unit wholesale price is higher than marginal costs for any finite value of $\phi$. The parties are therefore not able to avoid the double marginalization problem even though they use a two-part tariff. This implies that total channel profit is lower than what can be achieved under channel integration (only in the limit $\phi \rightarrow \infty$ do we have $w^{*}=c$ ). The reason why $w^{*}$ is set above marginal costs is simply that the manufacturer will otherwise have no incentives to invest in effort, and in equilibrium we have

$$
x^{*}=\frac{v-c}{N(\phi)+\phi} \text { and } q^{*}=\phi \frac{1+\phi}{2(N(\phi)+\phi)}(v-c) .
$$

Note that since $w^{*}$ is independent of $\alpha$, the same is true for $x^{*}$. The distribution of the bargaining power thus only determines the sign and size of the fixed fee $S$. The dividing line between slotting allowances $\left(S^{*}>0\right)$ and franchising fees $\left(S^{*}<0\right)$ can be found by solving for $S^{*}=0$ in equation (16):

$$
S^{*}=0 \quad \text { if } \quad \alpha=\widetilde{\alpha}(\phi) \equiv \frac{2 N(\phi)}{(\phi+2)(N(\phi)+\phi)} .
$$

The term $N(\phi)$ is positive if $\phi>\underline{\phi} \equiv(\sqrt{5}-1) / 2 \approx 0.62$, in which case $\widetilde{\alpha}(\phi)>0$.

We can now state:

Proposition 1 The market equilibrium yields slotting allowances if $\alpha<\widetilde{\alpha}(\phi)$ and franchising fees if $\alpha>\widetilde{\alpha}(\phi)$.

Suppose $\phi<\underline{\phi}$. From equations (15) and (18) we then see that $w^{*}>v$ and $\widetilde{\alpha}(\phi)<0$. This has the following interesting implication:

Proposition 2 Assume that $\phi \in\left(\frac{1}{2}, \underline{\phi}\right)$. Even if the retailer had the whole bargaining power $(\alpha=0)$, he would pay a fixed fee to the manufacturer $\left(S^{*}<0\right)$.

A fixed fee from the retailer to the manufacturer is commonly described as a franchising fee, and taken to imply that the manufacturer has the bargaining power. This is not true here, since a franchising fee may also be observed even if the whole bargaining power is in the hands of the retailer and $w>c$. The reason for this somewhat surprising result, is that $w^{*}>v$ if the marginal effort costs are sufficiently 
low (i.e. if $\phi<\underline{\phi}$ ). According to Remark 1 the manufacturer will then expect zero demand if she sets $x=0$. However, we also see from equation (12) that her profit will be negative if $S=0$ and she sets $x>0$. In order to fulfill the manufacturer's participation constraint, the retailer must thus pay a franchising fee (also for $\alpha=0$ ).

An example might be clarifying. Suppose that $\phi=0.55$. Equation (17) then implies that aggregate profit in the disintegrated channel is maximized if $x^{*}=2.48$, which from (15) requires that $w^{*}=1.37$. This implies that the manufacturer's investment costs are equal to $\frac{\phi}{2}\left(x^{*}\right)^{2}=1.70(v-c)^{2}$, while her variable profit is only $\left(w^{*}-c\right) q^{*}=1.45(v-c)^{2}$. Unless the manufacturer receives a franchising fee which at least covers this difference, she will not sign a contract with the retailer. Even if the retailer has the full bargaining power he must therefore pay the manufacturer a franchising fee, and from equation (16) we consequently find $S^{*}=-0.25(v-c)^{2}$ at $\alpha=0$.

Other things equal, the retailer's ability to demand slotting allowances is increasing in his bargaining power (decreasing in $\alpha$ ). However, Proposition 2 makes it clear that the retailer cannot demand any slotting allowances if $\phi$ is sufficiently low. Neither can there be any slotting allowances in the limit $\phi \rightarrow \infty$; the channel participants will clearly not want to induce any sales effort if the costs of doing so are infinitely high. In this case the equilibrium unit wholesale price will consequently be set equal to marginal costs $\left(\lim _{\phi \rightarrow \infty} w^{*}=c\right)$, leaving no operating profit to the manufacturer. The possibility of positive slotting allowances can therefore only arise for intermediate values of $\phi$. Differentiating equation (18) we consequently find that $\widetilde{\alpha}(\phi)$ is hump-shaped, as illustrated in Figure 1 . The peak is at $\widetilde{\alpha}(\bar{\phi}) \approx 0.37$, where $\bar{\phi} \approx 1.48$, such that there will be no slotting allowances if $\alpha>\widetilde{\alpha}(\bar{\phi})$.

We will observe franchising fees above the curve $\widetilde{\alpha}(\phi)$. To what extent we will observe slotting allowances below the curve, depends on the bargaining power of the retailer. Suppose that $\alpha=0.3$, as indicated by the dotted horizontal line in Figure 1. Slotting allowances then occur only in the shaded area. Outside this area the manufacturer receives a franchising fee, either because she is in a strong bargaining position or because it is necessitated to fulfill her participation constraint when marginal effort costs are "low" (c.f Proposition 2). 


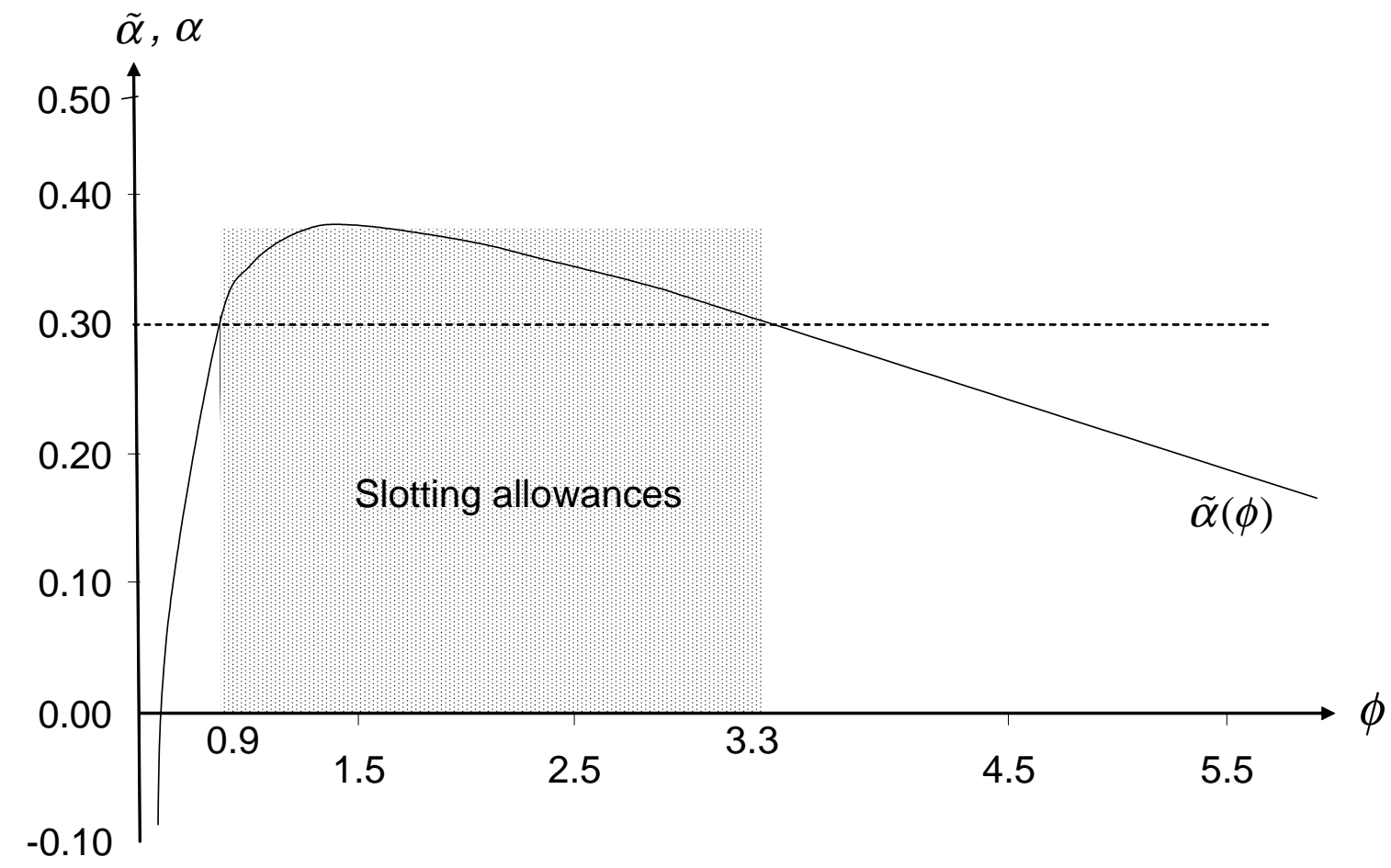

Figure 1: Occurance of slotting allowances.

From Proposition 1, and as illustrated in Figure 1, we have the following corollary:

Corollary 1: Assume that the retailer's bargaining power is sufficiently high that $\alpha<\widetilde{\alpha}(\bar{\phi})$. Then slotting allowances occur for intermediate levels of $\phi$. For polar cases, i.e. high or low values of $\phi$, slotting allowances will not be observed.

There seems to be a broad consensus that channel bargaining power has shifted from upstream firms to downstream firms in many industries over the last couple of decades, not least in the grocery sector. This generates a downward shift of the dotted line in Figure 1. In the limit as $\alpha \rightarrow 0$ (full retailer bargaining power) we see that there will be slotting allowances for all goods where $\phi>\underline{\phi}$, i.e. for goods where demand is not very sensitive to the manufacturer's effort level.

The present paper is partly motivated by the FTC (2003) report on the use of slotting allowances in the grocery sector. As discussed in the introduction, FTC states that with slotting allowances a retailer may find it optimal to offer relatively 
high wholesale prices. Thereby the manufacturer has incentives to invest more in non-contractible sales effort than would otherwise be the case, and the retailer can be compensated for the high wholesale prices through the slotting fee. While this is correct, it may leave the impression that wholesale prices and sales effort investments are higher with than without slotting allowances. That is not necessarily true. To see why, let us impose the restriction that $S=0$. Then the retailer's profit is simply equal to his profit margin times sales, $\pi_{r}=(p-w) q$. A higher unit wholesale price reduces the retailer's profit margin, but will also expand sales. At the outset, it is thus ambiguous whether $d \pi_{r} / d w$ is positive or negative. Using equations (1), (7), and (11) we find

$$
\left.\frac{d \pi_{r}}{d w}\right|_{S=0}=\underbrace{q \frac{d(p-w)}{d w}}_{-}+\underbrace{(p-w) \frac{d q}{d w}}_{+}=q \frac{1-\phi}{\phi} .
$$

To interpret this, note from (11) that $d x / d w=1 / \phi$. The manufacturer will thus undertake greater effort investments subsequent to an increase in $w$ the smaller $\phi$. Put differently, the smaller $\phi$, the larger is the positive shift in the demand curve that the retailer can generate by increasing $w$. For $\phi<1$ this effect is sufficiently strong to outweigh the drop in the retailer's profit margin (while the opposite is true for $\phi>1$ ). If the marginal effort costs (as measured by $\phi$ ) are sufficiently low, and $S=0$, the retailer may over-stimulate demand compared to what maximizes aggregate profit for the firms. More precisely, in the Appendix we prove the following:

Proposition 3 For services where demand is sensitive to the manufacturer's effort, $\phi<1$, unit wholesale prices and investments are lower with slotting allowances $\left(S^{*}>0\right)$ than without slotting allowances $(S=0)$.

Recall that slotting allowances will be observed under a two-part tariff if $\alpha<$ $\widetilde{\alpha}(\phi)$. Proposition 3 holds for any distribution of bargaining power between the retailer and the manufacturer where $\alpha<\widetilde{\alpha}(\phi)$, and it is easily verified that aggregate channel profit is always at least as high with as without slotting allowances.

The general insight from Proposition 3 is that the manufacturer's choice of effort level will become more efficient from a channel point of view (higher aggregate profit) 
if we go from a situation with only linear wholesale prices to one with slotting allowances. But in general we cannot say whether this leads to higher or lower investments.

\subsection{Welfare}

The main focus of this paper is on the occurrence of slotting allowances versus franchising fees when the manufacturer makes non-contractible sales effort. However, we will also briefly discuss welfare effects of slotting allowances, since this has been the subject of numerous public investigations and debates. Following the convention in the literature, we define welfare as the sum of consumer surplus $(C S)$ and aggregate profit (П):

$$
W=C S+\Pi \text {. }
$$

It is clear that aggregate profit cannot be lower with a two-part tariff $(t p)$ than with linear wholesale pricing $(l p)$, since the firms have one additional instrument at their disposal in the former case. For any distributions of bargaining power we therefore have:

$$
\Pi_{t p} \geq \Pi_{l p}
$$

While the ranking of profits between $t p$ and $l p$ is independent of $\alpha$, the same is not necessarily true for consumer surplus. To see why, note that the larger the retailer's bargaining power under $l p$, the lower is the unit wholesale price that he has to offer the manufacturer, other things equal. A lower wholesale price in turn translates into a lower end-user price. It can thus be shown that consumer surplus under $l p$ is decreasing in $\alpha ; d C S / d \alpha<0$. Specifically, this means that consumer surplus is higher if the whole bargaining power belongs to the retailer $(\alpha=0)$ than if it belongs to the manufacturer $(\alpha=1)$. In the Appendix we further show that consumer surplus under a two-part tariff is somewhere between these two extremes, such that we have: ${ }^{8}$

\footnotetext{
${ }^{8}$ Note that we do not need to specify who has the bargaining power with a two-part tariff; as
} 


$$
C S_{l p}^{\alpha=0}>C S_{t p}>C S_{l p}^{\alpha=1}
$$

It is consequently unclear how consumers are affected by a change from $l p$ to $t p$; they are more likely to lose the stronger the bargaining position of the retailer.

The explanation of why $C S_{t p}>C S_{l p}^{\alpha=1}$ is that the double marginalization problem is particularly pronounced if the manufacturer has the bargaining power and the firms use a linear wholesale tariff. Indeed, we will then have double marginalization even in the limit $\phi \rightarrow \infty$, since the manufacturer will always set $w>c$ under $l p$. Otherwise the firm will make no profit.

To see why $C S_{l p}^{\alpha=0}>C S_{t p}$, recall that the only reason why the retailer might prefer $w>c$ is to encourage the manufacturer to make effort investments. However, with a linear wholesale tariff an increase in $w$ has a direct negative effect on the retailer's profit. This is not so with a two-part tariff, since a higher $w$ then allows the retailer to charge a higher slotting fee, other things equal. This tends to make the retailer more willing to offer the manufacturer a high unit wholesale price. Indeed, he will be willing to increase $w$ at the expense of a higher end-user price and lower downstream profit as long as total channel profit increases. In this sense the double marginalization problem is magnified with a two-part tariff compared to a linear wholesale price where the retailer has the bargaining power. Thereby consumer surplus is lower in the former case.

With respect to total welfare, we can state the following:

Proposition 4 Welfare with a two-part wholesale tariff $(t p)$ is higher than with linear wholesale pricing (lp) if (i) the manufacturer has the full bargaining power $(\alpha=1)$, or (ii) the retailer has the full bargaining power $(\alpha=0)$ and $\phi \in(1 / 2, \underline{\phi})$ or $\phi \in(0.72,2.07)$.

Proof. See Appendix.

shown above, the value of $\alpha$ only determines the split of aggregate profit between the firms, and does not affect prices or effort levels. 


\subsection{How to Achieve the Integrated Channel Outcome}

The analysis above makes it clear that the manufacturer will not make any noncontractible effort investments unless $w>c$, and that this generates a double marginalization problem which implies that total profit is lower than in an integrated channel. In this section we shall briefly discuss revenue sharing, resale price maintenance (RPM) and delegation of retail pricing as ancillary restraints that may be used to solve this problem. In addition, we will discuss whether a disintegrated channel can achieve the same profit as an integrated channel if there are repeated interactions between the retailer and the manufacturer.

\subsubsection{Revenue Sharing}

Within the franchising literature it is often assumed that the franchisor may offer a three-part tariff to the franchisee; a lump-sum franchising fee, a unit wholesale price, and a revenue-sharing rate expressed as a fraction of the franchisee's gross revenues (see e.g. Lal, 1990). An analogous contract in the present case will be that the firms use a contract of the form $T_{r s}=\{S, w, \theta\}$, where $S$ is the slotting allowance, $w$ is the unit wholesale price, and $1-\theta$ is the fraction of the gross retail sales revenue that the retailer pays to the manufacturer (the subscript $r s$ indicates that revenue sharing is used in addition to a two-part tariff). We assume that $0<\theta \leq 1$. The timing structure is similar to the basic model. The profits of the retailer and the manufacturer are given by:

$$
\begin{gathered}
\pi_{r, r s}=(\theta p-w)(v+x-p)+S \\
\pi_{m, r s}=[(1-\theta) p+w-c](v+x-p)-S-\phi \frac{x^{2}}{2}
\end{gathered}
$$

Holding $x$ fixed, and solving the first-order condition $\partial \pi_{r, r s} / \partial p=0$ at stage 2 , we find that ${ }^{9}$

$$
p_{r s}=\frac{v+x}{2}+\frac{w}{2 \theta} .
$$

\footnotetext{
${ }^{9}$ Since $\partial^{2} \pi_{r, r s} / \partial p^{2}=-2 \theta$, the second-order condition is fulfilled if $\theta>0$.
} 
Comparing (4) and (23) we see that the retailer can ensure the same end-user price as under channel integration for any given $x$ if he sets the unit wholesale price equal to $\theta c$.Holding $p$ fixed, we further find from stage 2 that $\partial \pi_{m, r s} / \partial x=0$ which implies that $x=[p(1-\theta)+w-c] / \phi$. Using equation (23) and $w_{r s}=\theta c$ this yields:

$$
x_{r s}=\frac{(v-c)(1-\theta)}{2 \phi-(1-\theta)},
$$

From equations (5) and (24) we note that the firms in the limit can achieve the same effort level as under channel integration $\left(x_{r s} \rightarrow x_{i c}\right)$ if $\theta \rightarrow 0$. This in turn implies that $p_{r s} \rightarrow p_{i c}$. Consequently, the unit wholesale price is used as an instrument to implement the integrated channel price, whereas the revenue-sharing parameter is used to implement the integrated channel sales effort. The fixed fee $S$ depends on $\alpha$ as before.

\subsubsection{Resale Price Maintenance (RPM)}

Under Resale price maintenance (RPM) the retail price is decided by the manufacturer. A combination of RPM and a wholesale price may then be used to achieve the channel integration outcome. ${ }^{10}$ The fixed fee determines the distribution of the total channel profit. The double marginalization problem is then avoided by limiting the retailer's control over the retail price. Until recently, there have been general per se bans towards RPM both in The United States and in Europe. However, in June 2007 the US Supreme Court overruled the nearly one-hundred year old per se ban on RPM (Leegin Creative Leather Products, Inc. v. PSKS, 2007). ${ }^{11}$ Like other vertical restraints, RPM is now to be judged by the rule of reason, and RPM may then be an available instrument to solve the type of channel coordination problems considered in the present paper. ${ }^{12}$ However, despite the Leegin case there is reason to believe that RPM raises more anti-trust concerns compared to alternative vertical

\footnotetext{
${ }^{10}$ We would like to thank one of the referees for proposing this alternative.

${ }^{11}$ See Foros; Kind and Shaffer (2008) for a discussion of some implications of the Leegin decision.

${ }^{12}$ For an overview of the literature on RPM see Overstreet (1983) and Mathewson and Winter (1998).
} 
restraints, and the per se ban is still in effect in Europe. Besides, in practice, it is potentially a problem that under RPM the retail price is not decided by the player with most hands-on market experience (see, e.g., Rey and Tirole, 1986).

\subsubsection{Delegation of Retail Pricing}

Delegation of retail pricing may be an alternative solution to the double marginalization problem, and we shall briefly discuss how this may work out. To this end, assume that the retailer splits his activities between a headquarter (HQ) and a retail subsidiary, where the former is responsible for procurements (the bargaining with the manufacturer) and the latter for end-user pricing. We maintain the same basic timing structure as we have used earlier. This means that HQ bargains the wholesale contract with the manufacturer at stage 1 . The good is then sold from the HQ to the retail subsidiary at a unit transfer price $t$ that is possibly different from $w$. The retail subsidiary thus perceives $t$ as the real marginal costs when it determines the end-user price which maximizes its own profit at stage 2 (simultaneously with the manufacturer's choice of sales effort). If the retailer headquarters can credibly commit to the size of $t$ before the manufacturer decides her sales effort, the firms may achieve the same outcome as under channel integration (where the fixed fee $S$ depends on $\alpha$ ).

What begs a question is in particular whether the HQ has the ability to commit to an observable arm's length transfer price before the manufacturer decides the level of sales effort. If not, then the best the HQ can do is to set $t=w$, and delegation will not solve the double marginalization problem. This resembles the result in Hirshleifer (1956).

\subsubsection{Repeated interaction}

Due to the non-contractible nature of the manufacturer's sales effort, there exists a commitment problem for the disintegrated channel in a one-shot game with a simple two-part tariff. From the well-known "Folk theorem" in repeated games, we know that the use of appropriate trigger strategies to punish deviations from the 
joint profit maximization outcome can help solve the problem, provided that there is not too much discounting of future profits in an infinitely repeated game. ${ }^{13}$ Note, however, that we do not have to rely on tacit collusion between the parties, since we consider a vertical relationship where formal contracts are unlikely to raise any legal concerns from competition authorities. Note also that in the present model, the manufacturer is the only firm that has an incentive to deviate from the joint profit maximization solution. Any sharing of surplus according to Nash bargaining with $\alpha<1$ results in the manufacturer receiving a share $\alpha$ of the ex post surplus, while the full cost of the non-contractible retail sales effort is carried by the manufacturer $e x$ ante. This is similar to the problem of moral hazard in teams, and a possible solution could be to specify a contract where the manufacturer receives a disadvantageous share of the surplus if demand deviates sufficiently much from its expected value in one or several periods. ${ }^{14}$ An alternative approach, inspired by Hart and Moore (1988), could be to investigate the case where renegotiation is possible after the retailer and manufacturer have chosen prices and sales effort.

\section{Concluding remarks}

A manufacturer's incentives to undertake non-contractible investments depend on the profit margin on her sales to the retailer. Slotting allowances can facilitate such incentives by increasing unit wholesale prices. It is therefore tempting to conclude that slotting allowances should be particularly prevalent for product categories where the manufacturer's scope for undertaking non-contractible sales effort is relatively large. However, this is at odds with FTC's finding that slotting allowances are more commonly used for non-perishable products - where demand presumably is relatively insensitive to non-contractible sales effort - than for perishable products.

In this article we have set up a simple model with one manufacturer and one

\footnotetext{
${ }^{13}$ See, e.g., Friedman (1971) or Rubinstein (1979). Similarly, the joint profit maximization outcome can be supported by trigger strategies if, in a finite game of uncertain duration, there is sufficiently high probability that the game continues to the next period.

${ }^{14}$ See, e.g., Holmstrom (1982).
} 
retailer, and where the predictions from the model are consistent with the observations reported by FTC. For product categories where there is significant scope for stimulating demand through non-contractible sales effort by the manufacturer, even a retailer with full bargaining power may find it optimal to pay the manufacturer a franchising fee. On the other hand, we are more likely to see slotting allowances for goods where the scope of non-contractible effort is more limited. Our model thus accentuates that there is no one-to-one relationship between retailers' bargaining power and the frequency and size of slotting allowances.

To our knowledge there are few empirical analyses of whether the distribution of bargaining power differs between product categories. One exception is Sexton and Zhang (1996), who find support for increased retail bargaining power for agricultural products due to the severe inelasticity of supply. Furthermore, we observe that retailers with significant bargaining power provide support for product innovation to manufacturers, and such support may be interpreted as a fixed fee (i.e. a franchising fee). However, the empirical literature on slotting allowances (e.g. Sudhir and Rao, 2006, and Bloom et al, 2000) typically restricts the attention to cases with positive slotting allowances. There is thus a need for empirical analysis investigating the distribution of bargaining power and the use of slotting allowances as well as franchising fees across product categories.

Finally, the paper makes it clear that unit wholesale prices - and thus noncontractible demand-enhancing investments - may be lower with than without twopart wholesale tariffs. The total channel profit will obviously be higher when twopart tariffs are used compared to the case with linear wholesale pricing. However, in contrast to the case where it is the retailer who undertakes non-contractible sales effort, a two-part tariff is not sufficient to resemble the outcome under channel integration in the case at hand. The coordination problem is thus more difficult when it is the manufacturer who undertakes non-contractible sales effort compared to the case where the retailer determines both price and effort.

This may have consequences for vertical merger incentives. Since it is more difficult to resemble the channel integration outcome when the manufacturer undertakes non-contractible effort than when the retailer undertakes such effort, the incentives 
for vertical mergers may, all other things equal, be higher in the former than in the latter case.

\section{References}

Bloom, P.N., G.T. Gundlach, and J.P. Cannon (2000), "Slotting allowances and fees: Schools of thought and the view of practicing managers", Journal of Marketing, 64, 92-108.

Chu, W. (1992), "Demand signaling and screening in channels of distribution", Marketing Science, 11(4), 324-347.

Desai, P. (1997), "Advertising Fee in Business-Format Franchising", Management Science, 43(10), 1401-1419.

Desai, P. (2000), "Multiple messages to retain retailers: Signaling new product demand", Marketing Science, 19(4), 381-389.

Farrell, Joseph (2001), "Some thoughts on slotting allowances and exclusive dealing", US Department of Justice.

Federal Trade Commission (FTC) (2001), Report on the Federal Trade Commission Workshop on slotting allowances and other marketing practices in the grocery industry. Washington D.C, US Government Printing Office.

Federal Trade Commission (FTC) (2003), Slotting Allowances in the Retail Grocery Industry: Selected Case Studies in Five Product Categories. Washington D.C. November 2003.

Foros, Ø. and H.J. Kind (2008), "Do slotting allowances harm retail competition?", Scandinavian Journal of Economics, (forthcoming).

Foros, Ø, H.J. Kind and G. Shaffer (2008), "Resale Price Maintenance and Restrictions on Dominant Firm and Industry-Wide Adoption", Working Paper.

Friedman, J. (1971), "A non-cooperative equilibrium for supergames", Review of Economic Studies 38, 1-12

Hart, O. and J. Moore (1988), "Incomplete contracts and renegotiation", Econometrica 56, 755-785. 
Hirshleifer, J. (1956), "On economics of transfer pricing", Journal of Business, Vol. 29, 172-184.

Holmstrom, B. (1982), "Moral hazard in teams", Bell Journal of Economics 13, 324-340.

Klein, B. and J.D. Wright (2007), "The Economics of Slotting Contracts", Journal of Law and Economics, 50(3), 421-454.

Kuksov, D. and A. Pazgal (2007), "The Effects of Cost and Competition on Slotting Allowances", Marketing Science, 26(2), 259-267.

Lal, R. (1990). "Improving Channel Coordination through Franchising", Marketing Science, 9 (4), 299-318.

Lariviere, M. and V. Padmanabhan (1997), "Slotting allowances and new product introductions", Marketing Science, 16(2), 112-128.

Marx, L.M. and G. Shaffer (2007), "Up-front Payments and Exclusion in Downstream Markets", RAND Journal of Economics, forthcoming.

Mathewson, G.F. and R.A. Winter. (1998). The Law and Economics of Resale Price Maintenance, Review of Industrial Organization, 13, 405-427.

Overstreet, T. (1983). Resale Price Maintenance: Economic Theories and Empirical Evidence. Bureau of Economics Staff Report to the Federal Trade Commission.

Rao, A.R. and H. Mahi (2003), "The price of launching a new product: Empirical evidence on factors affecting the relative magnitude of slotting allowances", Marketing Science, 22(2), 246-268.

Rao, R.C. and S. Srinavasan (1995), "Why are Royalty Rates Higher in ServiceType Franchises?", Journal of Economics and Management Strategy, 4(1), 7-31.

Rey, P. and J. Stiglitz (1995), "The role of exclusive territories in producers' competition", RAND Journal of Economics, 26, 431-451.

Rey, P. and J. Tirole (1986), The Logic of Vertical Restraints, American Economic Review, 76(5),921-931.

Rubinstein, A. (1979), "Equilibrium in Supergames with the Overtaking Criterion", Journal of Economic Theory 21, 1-9.

Sexton, R. and M. Zhang. (1996), "A Model of Price Determination for Fresh Produce with Application to California Iceberg Lettuce.", American Journal of Agri- 
cultural Economics, 78(4), 924-934.

Shaffer, G. (1991), "Slotting allowances and retail price maintenance: A comparison of facilitating practices", RAND Journal of Economics, 22(1), 120-135.

Shaffer, G. (2005), "Slotting Allowances and Optimal Product Variety", B.E. Journals in Economic Analysis $\&$ Policy, 5 (3).

Sudhir, K. and V.R. Rao. (2006), "Do Slotting Allowances Enhance Efficiency or Hinder Competition?" Journal of Marketing Research, 43(2), 137-155.

Sullivan, M.W. (1997), "Slotting allowances and the market for new products", Journal of Law \& Economics, 40(2), 461-493.

Wilkie, W.L, D.M. Desrochers, and G.T. Gundlach (2002), "Marketing Research and Public Policy: The Case of Slotting Fees", Journal of Public Policy ES Marketing, $21(2), 275-288$.

\section{Appendix}

\section{Proof of Proposition 3:}

Let us consider the outcome under linear wholesale pricing, and introduce the constraint that $S=0$ on the bargaining game at stage 1 . The first order condition with respect to $w$ in (14) becomes

$$
\frac{d}{d w}\left[\left(\pi_{m}\right)^{\alpha}\left(\pi_{r}\right)^{1-\alpha}\right]=-\alpha \frac{(v-c)(w-c-\phi[v-w])}{2}+(w-c)(v-w)(1-\phi)
$$

To indicate how a restriction on pricing structure would influence prices and effort, we compare the outcome with linear wholesale pricing and a two-part tariff. By inserting for $w=w^{*}(15)$ into (25), the first order condition (25) becomes

$$
\left.\frac{d}{d w}\left[\left(\pi_{m}\right)^{\alpha}\left(\pi_{r}\right)^{1-\alpha}\right]\right|_{w=w^{*}}=2(1-\phi) S^{*}
$$

where $S^{*}$ is given by (16). When equation (26) is positive, the unit wholesale price (and consequently the level of manufacturer's sales effort) will be higher under linear wholesale pricing than with a two-part tariff. This is the case if $\alpha<\widetilde{\alpha}(\phi)$, such that $S^{*}>0$, and $\phi<1$. QED. 


\section{Proof of inequality (22) and Proposition 4:}

With the demand function (1) we can express consumer surplus as

$$
C S=\frac{q^{2}}{2} .
$$

Inserting for (17) into (27) we find that consumer surplus under a two-part tariff equals

$$
C S_{t p}=\frac{1}{2}\left\{\frac{\phi(1+\phi)}{2[N(\phi)+\phi]}\right\}^{2}(v-c)^{2} .
$$

Using (12) and (15) we further find that $\Pi_{t p}=\frac{\phi(\phi+2)}{4(N(\phi)+\phi)}(v-c)^{2}$. Summing $C S_{t p}$ and $\Pi_{t p}$, welfare under a two-part tariff can be expressed as

$$
W_{t p}=\frac{\phi\left(7 \phi+10 \phi^{2}-4+3 \phi^{3}\right)}{8[N(\phi)+\phi]^{2}}(v-c)^{2} .
$$

The outcome of the second stage, where the manufacturer chooses effort level and the retailer chooses the end-user price, is given by equation (11), independent of whether we have a two-part wholesale tariff or only linear wholesale pricing. Suppose that we have a linear wholesale price, and that the manufacturer has the whole bargaining power. Solving $w_{l p}=\arg \max \pi^{M}$ in this case yields

$$
\begin{aligned}
w_{l p}^{\alpha=1} & =\frac{v+c}{2} \text { and } x_{l p}^{\alpha=1}=\frac{1}{2 \phi}(v-c) ; \\
C S_{l p}^{\alpha=1} & =\frac{(1+\phi)^{2}}{32 \phi^{2}}(v-c)^{2} \quad \text { and } W_{l p}^{\alpha=1}=\frac{3+6 \phi+7 \phi^{2}}{32 \phi^{2}}(v-c)^{2} .
\end{aligned}
$$

If instead the retailer has the bargaining power, we solve $w_{l p}=\arg \max \pi^{R}$. We then find

$$
\begin{aligned}
& \phi \quad>1: w_{l p}^{\alpha=0}=c ; x_{l p}^{\alpha=0}=0 ; C S_{l p}^{\alpha=0}=\frac{1}{8}(v-c)^{2} ; W_{l p}^{\alpha=0}=\frac{3}{8}(v-c)^{2} . \\
& \phi \quad \in\left(\frac{1}{2}, 1\right): w_{l p}^{\alpha=0}=v ; x_{l p}^{\alpha=0}=\frac{v-c}{\phi} ; C S_{l p}^{\alpha=0}=\frac{1}{8 \phi^{2}}(v-c)^{2} ; W_{l p}^{\alpha=0}=\frac{3}{8 \phi^{2}}(v-c)^{2} .
\end{aligned}
$$

For consumer surplus we now find

$$
\begin{aligned}
& \alpha=1: C S_{t p}-C S_{l p}^{\alpha=1}=\frac{\left(1-\phi^{2}\right)^{2}\left[N(\phi)+\phi+2 \phi^{2}\right]}{32[N(\phi)+\phi]^{2} \phi^{2}}(v-c)^{2}>0 \\
& \alpha=0 \text { and } \phi \in\left(\frac{1}{2}, 1\right): C S_{t p}-C S_{l p}^{\alpha=0}=\frac{-(1-\phi)\left(\phi^{2}+\phi-1\right)(v-c)^{2}}{8 \phi^{2}[N(\phi)+\phi]^{2}\left[N(\phi)+\phi+\phi^{2}+\phi^{3}\right]^{-1}}<0 \\
& \alpha=0 \text { and } \phi>1: C S_{t p}-C S_{l p}^{\alpha=0}=\frac{-(\phi-1)(v-c)^{2}}{8[N(\phi)+\phi]^{2}\left[N(\phi)+2 \phi+\phi^{2}\right]^{-1}}<0 .
\end{aligned}
$$


The inequalities in (33) prove (22).

For welfare we have

$$
\begin{aligned}
& \alpha=1: W_{t p}-W_{l p}^{\alpha=1}=\frac{\left(1-\phi^{2}\right)^{2}(v-c)^{2}}{32[N(\phi)+\phi]^{2} \phi^{2}\left(5 \phi^{2}+6 \phi-3\right)^{-1}}>0 \text { for } \phi \neq 1 \\
& \alpha=0 \text { and } \phi \in\left(\frac{1}{2}, 1\right): W_{t p}-W_{l p}^{\alpha=0}=\frac{\left(3 \phi^{4}+7 \phi^{3}-9 \phi+3\right)(v-c)^{2}}{8 \phi^{2}[N(\phi)+\phi]^{2}\left(\phi^{2}+\phi-1\right)^{-1}}<0 \text { for } \phi \in(\underline{\phi}, 0.72) \\
& \alpha=0 \text { and } \phi \geq 1: W_{t p}-W_{l p}^{\alpha=0}=\frac{\left(\phi^{2}+8 \phi-2 \phi^{3}-3\right)(v-c)^{2}}{8[N(\phi)+\phi]^{2}}<0 \text { for } \phi>2.07 .
\end{aligned}
$$

Proposition 4 follows from (34). 


\section{CESifo Working Paper Series}

for full list see www.cesifo-group.org/wp

(address: Poschingerstr. 5, 81679 Munich, Germany, office@cesifo.de)

2333 Erkki Koskela and Panu Poutvaara, Outsourcing and Labor Taxation in Dual Labor Markets, June 2008

2334 Philippe Choné and Laurent Linnemer, Optimal Litigation Strategies with Signaling and Screening, June 2008

2335 Albert Solé-Ollé and Pilar Sorribas-Navarro, Does Partisan Alignment Affect the Electoral Reward of Intergovernmental Transfers?, June 2008

2336 Antonio Cabrales and Piero Gottardi, Markets for Information: Of Inefficient Firewalls and Efficient Monopolies, June 2008

2337 Sumon Majumdar and Sharun W. Mukand, The Leader as Catalyst - on Leadership and the Mechanics of Institutional Change, June 2008

2338 Ulrich Hange, Tax Competition, Elastic Labor Supply, and Growth, June 2008

2339 Guy Laroque and Bernard Salanié, Does Fertility Respond to Financial Incentives?, June 2008

2340 Adriano Paggiaro, Enrico Rettore and Ugo Trivellato, The Effect of Extending the Duration of Eligibility in an Italian Labour Market Programme for Dismissed Workers, June 2008

2341 Helmut Seitz, Minimum Standards, Fixed Costs and Taxing Autonomy of Subnational Governments, June 2008

2342 Robert S. Chirinko, Leo de Haan and Elmer Sterken, Asset Price Shocks, Real Expenditures, and Financial Structure: A Multi-Country Analysis, July 2008

2343 Wolfgang Leininger, Evolutionarily Stable Preferences in Contests, July 2008

2344 Hartmut Egger and Udo Kreickemeier, Fairness, Trade, and Inequality, July 2008

2345 Ngo Van Long and Bodhisattva Sengupta, Yardstick Competition, Corruption, and Electoral Incentives, July 2008

2346 Florian Baumann, Employment Protection: The Case of Limited Enforceability, July 2008

2347 Alessandro Balestrino, Cinzia Ciardi and Claudio Mammini, On the Causes and Consequences of Divorce, July 2008

2348 Dirk Schindler and Benjamin Weigert, Insuring Educational Risk: Opportunities versus Income, July 2008 
2349 Lammertjan Dam and Ben J. Heijdra, The Environmental and Macroeconomic Effects of Socially Responsible Investment, July 2008

2350 Avner Greif, Contract Enforcement and Institutions among the Maghribi Traders: Refuting Edwards and Ogilvie, July 2008

2351 Helmuth Cremer, Philippe De Donder, Dario Maldonado and Pierre Pestieau, Habit Formation and Labor Supply, July 2008

2352 Francesco Menoncin and Paolo M. Panteghini, The Johansson-Samuelson Theorem in General Equilibrium: A Rebuttal, July 2008

2353 Michael Kaganovich and Itzhak Zilcha, Alternative Social Security Systems and Growth, July 2008

2354 Keith Blackburn, Kyriakos C. Neanidis and M. Emranul Haque, Corruption, Seigniorage and Growth: Theory and Evidence, July 2008

2355 Edward Castronova, A Test of the Law of Demand in a Virtual World: Exploring the Petri Dish Approach to Social Science, July 2008

2356 Harald Badinger and Peter Egger, GM Estimation of Higher-Order Spatial Autoregressive Processes in Cross-Section Models with Heteroskedastic Disturbances, July 2008

2357 Wolfgang Buchholz and Jan Schumacher, Discounting the Long-Distant Future: A Simple Explanation for the Weitzman-Gollier-Puzzle, July 2008

2358 Luca Anderlini, Leonardo Felli and Alessandro Riboni, Statute Law or Case Law?, July 2008

2359 Guglielmo Maria Caporale, Davide Ciferri and Alessandro Girardi, Are the Baltic Countries Ready to Adopt the Euro? A Generalised Purchasing Power Parity Approach, July 2008

2360 Erkki Koskela and Ronnie Schöb, Outsourcing of Unionized Firms and the Impacts of Labour Market Policy Reforms, July 2008

2361 Francisco Alvarez-Cuadrado and Ngo Van Long, A Permanent Income Version of the Relative Income Hypothesis, July 2008

2362 Gabrielle Demange, Robert Fenge and Silke Uebelmesser, Financing Higher Education and Labor Mobility, July 2008

2363 Alessandra Casarico and Alessandro Sommacal, Labor Income Taxation, Human Capital and Growth: The Role of Child Care, August 2008

2364 Antonis Adam, Manthos D. Delis and Pantelis Kammas, Fiscal Decentralization and Public Sector Efficiency: Evidence from OECD Countries, August 2008 
2365 Stefan Voigt, The (Economic) Effects of Lay Participation in Courts - A Cross-Country Analysis, August 2008

2366 Tobias König and Andreas Wagener, (Post-)Materialist Attitudes and the Mix of Capital and Labour Taxation, August 2008

2367 Ximing Wu, Andreas Savvides and Thanasis Stengos, The Global Joint Distribution of Income and Health, August 2008

2368 Alejandro Donado and Klaus Wälde, Trade Unions Go Global!, August 2008

2369 Hans Gersbach and Hans Haller, Exit and Power in General Equilibrium, August 2008

2370 Jan P.A.M. Jacobs and Jan-Egbert Sturm, The Information Content of KOF Indicators on Swiss Current Account Data Revisions, August 2008

2371 Oliver Hülsewig, Johannes Mayr and Timo Wollmershäuser, Forecasting Euro Area Real GDP: Optimal Pooling of Information, August 2008

2372 Tigran Poghosyan and Jakob de Haan, Determinants of Cross-Border Bank Acquisitions in Transition Economies: A Latent Class Analysis, August 2008

2373 David Anthoff and Richard S.J. Tol, On International Equity Weights and National Decision Making on Climate Change, August 2008

2374 Florian Englmaier and Arno Schmöller, Reserve Price Formation in Online Auctions, August 2008

2375 Karl Farmer, Birgit Friedl and Andreas Rainer, Effects of Unilateral Climate Policy on Terms of Trade, Capital Accumulation, and Welfare in a World Economy, August 2008

2376 Monika Bütler, Stefan Staubli and Maria Grazia Zito, The Role of the Annuity’s Value on the Decision (Not) to Annuitize: Evidence from a Large Policy Change, August 2008

2377 Inmaculada Martínez-Zarzoso, The Impact of Urbanization on $\mathrm{CO}_{2}$ Emissions: Evidence from Developing Countries, August 2008

2378 Brian Roberson and Dmitriy Kvasov, The Non-Constant-Sum Colonel Blotto Game, August 2008

2379 Ian Dew-Becker, How Much Sunlight Does it Take to Disinfect a Boardroom? A Short History of Executive Compensation Regulation, August 2008

2380 Cécile Aubert, Oliver Falck and Stephan Heblich, Subsidizing National Champions: An Evolutionary Perspective, August 2008

2381 Sebastian Buhai, Miguel Portela, Coen Teulings and Aico van Vuuren, Returns to Tenure or Seniority?, August 2008 
2382 Erkki Koskela and Jan König, Flexible Outsourcing, Profit Sharing and Equilibrium Unemployment, August 2008

2383 Torberg Falch and Justina AV Fischer, Does a Generous Welfare State Crowd out Student Achievement? Panel Data Evidence from International Student Tests, September 2008

2384 Pedro Gomes and François Pouget, Corporate Tax Competition and the Decline of Public Investment, September 2008

2385 Marko Koethenbuerger, How Do Local Governments Decide on Public Policy in Fiscal Federalism? Tax vs. Expenditure Optimization, September 2008

2386 Ronald McKinnon and Gunther Schnabl, China’s Exchange Rate Impasse and the Weak U.S. Dollar, September 2008

2387 Yan-Leung Cheung, Yin-Wong Cheung and Alan T.K. Wan, A High-Low Model of Daily Stock Price Ranges, September 2008

2388 Louis Eeckhoudt and Harris Schlesinger, Changes in Risk and the Demand for Saving, September 2008

2389 Carsten Hefeker and Blandine Zimmer, Uncertainty and Fiscal Policy in an Asymmetric Monetary Union, September 2008

2390 Jay Pil Choi and Byung-Cheol Kim, Net Neutrality and Investment Incentives, September 2008

2391 Marcel Gérard, Financing Bologna, the Internationally Mobile Students in European Higher Education, September 2008

2392 Annette Alstadsæter and Knut Reidar Wangen, Corporations' Choice of Tax Regime when Transition Costs are Small and Income Shifting Potential is Large, September 2008

2393 António Afonso and Christophe Rault, 3-Step Analysis of Public Finances Sustainability: the Case of the European Union, September 2008

2394 Betsey Stevenson and Justin Wolfers, Economic Growth and Subjective Well-Being: Reassessing the Easterlin Paradox, September 2008

2395 Bernhard Eckwert and Itzhak Zilcha, Private Investment in Higher Education: Comparing Alternative Funding Schemes, September 2008

2396 Øystein Foros, Hans Jarle Kind and Jan Yngve Sand, Slotting Allowances and Manufacturers' Retail Sales Effort, September 2008 